\title{
Una pandemia que desbarata el presente y abre incógnitas, retos e incertidumbres sobre el futuro ${ }^{1}$
}

\section{A pandemic that modifies the present and open incognites, challenges and uncertainties about the future}

$\frac{\text { Rafael Grasa Hernández² }}{\text { DOI: https://doi.org/10.22490/26655489.4476 }}$

Empezaremos recordando una anécdota de hace ya bastantes décadas: André Malraux preguntó al entonces primer ministro chino, Zhou Enlai, acerca de las lecciones y balance que hacía de la Revolución Francesa. La respuesta, mezcla de sensatez y de boutade, fue: "aún es demasiado pronto para poder afirmar con seguridad nada al respecto".

La frase señala, aunque quizás de manera exagerada, la necesidad de no emitir juicios apresurados y categóricos sobre fenómenos de actualidad y procesos de cambio en curso. No todo lo que en un primer momento parece histórico, un acontecimiento sin precedentes, que cambiará las tendencias y el curso de la historia, lo es -o lo será- final y realmente. De hecho, la mayoría de dichos sucesos acaban no siendo parteaguas, puntos de inflexión o catalizadores de cambios bruscos de tendencia. Como nos recuerdan las estadísticas y las matemáticas, que se produzcan eventos atípicos, incluso recurrentes, es más fácil que cambiar tendencias, en particular de largo aliento.

De ahí la importancia de recordar la prudencia de la respuesta de Zou Enlai en lo que nos ocupa: cosas que se escribieron en marzo de 2020, cuando ya era claro que la epidemia se había

1 El presente texto, al ser una introducción y por ende no estar sujeto a revisión de pares, se ha autocontenido voluntaria y drásticamente en cuanto a citas y referencias. Como se ha dicho en la nota introductoria al presente número de la revista, Análisis Jurídico-Político seguirá ocupándose del tema.

2 Profesor titular de Relaciones Internacionales de la Universidad Autónoma, coordinador del Máster Universitario en "Relaciones Internacionales, Seguridad y Desarrollo" y coordinador del doctorado "Politics, Policies and International Relations" de la misma universidad. Profesor colaborador de la ECJP de la UNAD, coeditor de Análisis Jurídico-Político y coordinador de la presente sección. Orcid 0000-0002-4385-7915. rafael.grasa@uab.cat. 
convertido en pandemia y las cuarentenas y confinamientos eran habituales en todas las regiones del planeta, no aguantan ocho o nueve meses después la prueba de la contrastación fáctica.

Veamos pues algunas evidencias y algunos interrogantes respecto de un presente, el previsto para 2020, desbaratado por la pandemia y retos, incertidumbres e incógnitas para el futuro, a corto y medio plazo.

\section{La pandemia y su impacto en los cambios en el mundo y en el sistema}

Desde enero de 2020, cuando se supo de la proliferación de contagios humanos del nuevo coronavirus (SARS-CoV-2) en la población china de Wuhan que iba a dar lugar a la enfermedad y luego pandemia conocida como COVID-19, muchas veces se olvidó la prudencia del consejo que abre este texto: menudearon, por el contrario, las referencias a que nada iba a ser como antes, que la pandemia lo cambiaba todo y que nada sería igual tras ella. Hubo quien habló de un retorno al mundo previo a la globalización, incluso sin recordar que el proceso de mundialización tiene cinco siglos de historia y que, por ejemplo, en términos comparativos, la segunda mitad del siglo XIX presenta rasgos de globalización comercial y económica superiores a los registrados en los años ochenta del siglo XX.

En el caso concreto del impacto geopolítico y geoeconómico de la pandemia podemos identificar dos grandes enfoques: uno sostiene que la pandemia acelera tendencias ya preexistentes; otro afirma que la crisis generada por la pandemia tiene un efecto disruptivo sobre lo existente y que provocará el surgimiento de un mundo muy diferente del actual. En forma resumida, podemos denominar sucintamente ambos enfoques como acelerador y disruptivo.

Y lo cierto es que ambos son perceptibles en la realidad fáctica en lo que, a finales de 2020, podemos ya saber con mayor certeza de la que supone la pandemia para el mundo, en particular para el sistema internacional y los procesos de globalización. Hay elementos de aceleración de procesos ya existentes y elementos disruptivos, al menos a corto y medio plazo. 
Hay que recordar en primer lugar lo esencial: la pandemia irrumpió en un proceso de cambio en curso, en un paisaje en plena transformación, con tendencias de largo aliento y cambio acumulativo y episodios convulsos iniciados al fin de la guerra fría, a finales de 1989 . A principios de 2020, antes de que se conociera la existencia de la pandemia presente, el mundo se caracterizaba ya por la incertidumbre como rasgo perdurable y constatable, así como por un incremento significativo de la impredecibilidad, al menos en comparación con la "quietud" constante de la etapa de la guerra fría y el enfrentamiento Este/Oeste.

Técnicamente, podemos decir, como rasgo evolutivo, que el sistema internacional de posguerra fría está recorrido por dos tipos de cambios: el primero, constante y cuasi imperceptible, al actuar por acumulación, los cambios de "lluvia fina" o cambios de largo plazo, que poco a poco, como sucede con los fenómenos climáticos habituales en la dimensión temporal geológica, generan cambios importantes en el paisaje internacional, como la extensión de los estados-nación o la propia globalización; el segundo, más "traumático" o catastrófico, es el derivado de choques de placas tectónicas, es decir, el producido por movimientos y contactos bruscos entre las placas tectónicas (brechas y fracturas en el sistema), que generan terremotos y eventos impactantes y, que, al final, acaban con acomodaciones temporales de las diversas "placas" estructurales del sistema. En suma, estabilidad y cambio de lluvia fina hasta el próximo choque de placas.

Lo característico y básico es que el segundo tipo de cambio, los choques fuertes y perceptibles de capas tectónicas, aceleran, visibilizan e intensifican los impactos del cambio del primer tipo, $y$, en algunos casos, alteran fuertemente sus tendencias y rasgos definitorios. Las alteraciones derivadas de ambos procesos de cambio se entremezclan y pueden darse simultáneamente. Dicho de otra forma, no todos los choques de placas tectónicas, pese a que su impacto inicial parezca trascendental, alteran las reglas de juego, no todos son productores de cambio de reglas ("game-changer", en la terminología al uso).

Las pandemias, la actual -derivada de la enfermedad bautizada como COVID-19- y muchas anteriores, son potencialmente sucesos del segundo tipo, choques de placas tectónicas. Recordemos que virus y bacterias han acompañado siempre la evolución humana, a través de epidemias recurrentes que, en diferentes momentos y teniendo en cuenta que no siempre el mundo ha sido como ahora plenamente planetario o global, han adoptado la forma de 
pandemias; es decir, de enfermedades de alcance planetario, al menos del "mundo" conocido en cada momento. Concretamente, la historia de la humanidad conoce cinco grandes pandemias, que han conformado nuestra historia como especie: viruela, sarampión, gripe "española", peste negra y sida/VIH, ordenadas de mayor a menor letalidad acumulada. Concretamente, de 300 a 40 millones de muertes de mayor a menor. Tampoco es la primera epidemia, e incluso pandemia, que se produce por zoonosis, es decir mediante el salto de un virus, vía mutación, de un animal al ser humano. Ni es la primera epidemia provocada por un coronavirus, como nos recuerda el episodio anterior del SARS, síndrome respiratorio agudo grave.

Así las cosas, como veremos, la pandemia del COVID19 ha alterado fuertemente tendencias que ya existían, nos ha devuelto la percepción de la fragilidad de la vida y de las sociedades humanas, pese a la compresión del espacio y del tiempo que caracteriza la fase de globalización y, eso sí, ha provocado un fuerte shock emocional, individual y colectivo. Pascal Boniface ${ }^{3}$ ha propuesto por ello definir el impacto que nos causó la pandemia como una sideración, según el diccionario una patología temporal, un "estado de detención súbita y casi completa de las funciones generales orgánicas, generalmente a consecuencia de un choque nervioso traumático, acción de corrientes eléctricas, rayo, apoplejía, etcétera". O, como dicen en psiquiatría, también hablando de sideración, "un cese brusco y total de las reacciones emocionales y motoras, bajo el efecto de un shock mental muy fuerte".

En suma, algo aparentemente imprevisible, totalmente inesperado, increíble. Aunque, como vamos a ver, en modo alguno fue inesperado e imprevisible.

\section{Algunas evidencias: la pandemia no ha sido un cisne negro ni algo que no hubiera sido previsto}

Nassim Nicholas Taleb ${ }^{4}$ dedicó un libro influyente al impacto de lo altamente improbable; es decir, lo que denominamos un cisne negro. Lo cierto es que, como cuenta al inicio del libro, los europeos estaban convencidos antes del descubrimiento de Australia de que todos los cisnes eran blancos, sin evidencia

3 Véase: Pascal Boniface, Géopolitique del COVID-19. Ce qui nos révèle la crise du coronavirus, Paris, Éditions Eyrolles, 2020.

4 Nassib Nicholas Talen. The Black Swan, Nueva York, Random House, 2007. 
empírica en contra, hasta que se avistaron de dicho color en Australia. De ello se deriva una debilidad del aprendizaje humano, basado en las generalizaciones basadas en el aprendizaje o la observación: la visión contrastada de un cisne negro, un suceso altamente improbable, supone invalidar siglos o milenios de visiones confirmatorias de millones de cisnes blancos previos.

De ello infiere Taleb que un cisne negro es un fenómeno que, epistemológicamente, se caracteriza por tres rasgos: 1) rareza e improbabilidad, puesto que nada del pasado permitía que fuera una posibilidad verosímil; 2) impacto tremendo en las personas y sociedades que los ven; $y, 3$ ) explicaciones a posteriori del fenómeno, o predictibilidad retrospectiva (no prospectiva), derivada de la naturaleza humana, que gusta de que la vida sea explicable y predictible, es decir, que gusta de validar lo que sucede, por improbable que sea. En suma, los cisnes negros son improbables, provocan un impacto muy grande y generan explicaciones a posteriori.

Según Taleb, unos cuantos cisnes negros explican la evolución de nuestras civilizaciones, entre los últimos Google o YouTube. En todo caso, dejando de lado ahora las interesantes argumentaciones de Taleb sobre teoría del conocimiento y el impacto acumulativo de los diversos cisnes negros, hay que insistir por tanto en que un cisne negro es, conceptualmente, un evento altamente improbable, impredecible prospectivamente y con gran impacto.

Pues bien, la primera cosa que podemos afirmar es que la pandemia no fue un cisne negro, pese a su ya mencionado gran impacto, hasta devenir una auténtica sideración. La inevitabilidad de una pandemia como la que estamos sufriendo había sido claramente establecida desde hacía más de una década, en la producción de ficción (películas y novelas), y, sobre todo, en los trabajos académicos y prospectivos, a partir de epidemias como la gripe aviar, el ébola o el SARS. Sin ánimo de exhaustividad, basta con recordar los informes predictivos de la CIA, múltiples libros blancos y estrategias de seguridad y defensa de los países OCDE, informes de la OMS e incluso una ahora célebre conferencia TEDx de Bill Gates en marzo de 2015.

En general, ficción e informes académicos decían lo mismo: el peligro más importante al que se enfrenta la humanidad no es nuclear, sino sanitario y, una vez llegada la pandemia, esta tendrá un 
enorme impacto social y sanitario y, solían decir, el origen de dicha pandemia puede darse en regiones de gran densidad demográfica y con proximidad casi total entre espacios salvajes y espacios urbanizados, al extenderse constantemente la frontera agrícola hacia zonas selváticas. Sólo meses antes de la comunicación del Gobierno de China de la epidemia en Wuhan, a finales de 2019, la OMS había alertado de los riesgos, una vez más.

Por tanto, la pandemia no era un cisne negro, ni un evento imprevisible. $Y$, sin embargo, fue percibido como tal, en particular en el mundo occidental. Lo sorprendente, en particular teniendo en cuenta que situaciones de riesgo como el vivido estos meses estaban descritas en muchas de las estrategias de seguridad nacional de los países OCDE, es por qué no se habían tomado previsiones. Gobernar, recuérdese, supone prevenir y, desde 1987 al menos (accidente nuclear de Chernóbil), parece claro que el principio de precaución no fue utilizado, en particular en Occidente.

¿Por qué? Probablemente por una serie de razones combinadas. Primero, porque prevenir es caro y expone a críticas, como pasó en parte de los países OCDE en alertas anteriores como con la gripe aviar o el ébola, si las disposiciones y cambios derivados de la prevención no llegan a ser necesarios. De hecho, incluso cuando las medidas preventivas resultan útiles y tienen éxito, parecen caras para muchos, porque, justamente, al impedir o aliviar la catástrofe invisibilizan parte de lo que hubiera sucedido. Segundo, en el caso de la OCDE y el mundo occidental, merced al sentimiento, falso, de superioridad respecto a pandemias y tragedias que se consideraban limitadas, 0 al menos especialmente graves, sólo a África o Asia. Propias, en suma, de regiones poco desarrolladas, densamente pobladas, con malos hábitos de higiene y sistemas sanitarios débiles. Por decirlo rápido, en un mundo en que la política depende cada vez más de la opinión publicada y de las críticas, el riesgo de hacer de más, medido en "capital de oportunidad política", acabó superando con creces el de no hacer bastante. El fenómeno se dio tanto en los años anteriores y las crisis que permitían predecir (entre 2003 y 2014) y en especial en los meses de enero a marzo de 2020. Se aplicó, en suma, el conocido sesgo de normalidad: nada de que inquietarse, con algunas excepciones en el mundo occidental (Alemania) y, eso sí, muchas más en la región asiática. 
Por consiguiente, aunque ni se trataba de un cisne negro ni de algo imprevisible, lo cierto es que la pandemia supuso una crisis en el mundo. Y lo característico de una crisis es justamente que, pese a que haya evidencia de que pueden darse, siempre se presentan de improviso, cuando nadie las espera.

\section{El impacto acelerado de los cambios en curso: algunas catas}

La llegada de la crisis originada por la pandemia muestra algunos de los rasgos del sistema ya detectados, aunque, como hemos dicho, los va a acelerar y a amplificar.

El primero es que ya en enero de 2020, cuando el coronavirus se expandía, pero aún no era una pandemia, el mundo ya era un lugar desigual, asimétrico, desorientado y con falta de sincronización en cuanto a su gobernanza.

Y el impacto de la pandemia ha puesto eso de manifiesto con especial gravedad: aunque la enfermedad tiene un alcance global (más de 80 millones de contagiados a final de año), ni su impacto sanitario, económico y social es el mismo, como tampoco ha afectado a todas las personas por igual el confinamiento y las consecuencias sociosanitarias de la pandemia. O lo que es lo mismo: la pandemia ha mostrado con claridad la tendencia constante a amplificar las desigualdades preexistentes. Y ello con algunas sorpresas, como el muy menor impacto del previsto en regiones como África y la gravedad de lo acaecido en grandes potencias como Estados Unidos de América o Rusia.

El caso de América Latina y el Caribe es significativo al respecto: la crisis ha tenido un impacto severo en una región recorrida por problemas estructurales no resueltos, la región más desigual y con mayor violencia urbana del planeta y con reformas políticas y socioeconómicas largamente pospuestas. El resultado ha sido, además de cientos de miles de muertes, una profundización de la desigualdad, la pobreza, la polarización política, la corrupción, la delincuencia y la violencia directa, así como de la debilidad estatal.

En términos globales, destacan diversas tendencias claras: la resiliencia social, que se mantiene; el deterioro democrático y la deriva autoritaria, agudizado por las medidas restrictivas -aunque 
necesarias en muchos casos- de los derechos fundamentales para contener la propagación del coronavirus, sin olvidar retrasos en procesos electorales; el recurso, al aplicar mecanismos de alerta y emergencia, a las fuerzas armadas para tareas de apoyo, a la policía e incluso a funcionarios de sanidad (transporte de pacientes y de insumos médicos), en algunos casos con instrucción adicional y ad hoc, pero también con incremento de poderes en áreas controversiales como la libertad de circulación, reunión y asamblea; e incremento del descontento social, pese a las dificultades que la pandemia supuso para el ciclo de protestas sociales muy activo en 2019 en el cono sur de la región. Adicionalmente, el impacto desigual de la pandemia, acelerando y magnificando tendencias, se nota también en los colectivos y sectores sociales más afectados: mujeres, comunidad LGBTI y pueblos originarios, donde la desigualdad de origen, la desprotección y el desigual acceso a la justicia han agudizado los problemas.

Un segundo rasgo, como tendencia acelerada, que parece despuntar en todo el mundo, es la recuperación del descontento y la protesta social, tras un período de confinamiento temporal de la indignación, con más fuerza, nuevas razones y formas. 2019 acabó con un ciclo alto de protestas sociales en muchas regiones del mundo, que parecía iba a seguir durante 2020, que se frenó durante la primera ola de la pandemia, pero que ha vuelto a resurgir a partir de mediados de año, con el caso paradigmático de "Black Lives Matter" y los procesos de securitización acaecidos aprovechando la emergencia sanitaria.

Señalaremos, como tercer rasgo, la aceleración de tendencias desglobalizadoras ya presentes en los últimos años, una crisis económica y no solo de crecimiento que ha acentuado el impacto aún presente de la crisis de 2008, y, en general, una economía desnortada y la proliferación de propuestas heterodoxas en muchos países. Sin ánimo de exhaustividad, durante la pandemia hemos visto cosas como: precios negativos del petróleo; disociación de los oligopolios digitales del resto de la economía; incremento, con aplauso incluido de los organismos financieros, de la deuda pública, con programas de ayuda inéditos por su magnitud y ambición en la UE; la aprobación de propuestas denostadas en muchos países, como la renta mínima en España, por ejemplo. 
Un cuarto rasgo, especialmente relevante, es la creciente importancia de la tecnología como factor y nueva frontera del poder, con especial relevancia en la configuración y reconfiguración geopolítica. La pandemia ha puesto en lugar preferente de la agenda temas como la tecnología 5G, las apps de nueva generación y el internet de las cosas, la importancia estratégica y económica de los datos masivos (big data), en el marco de la tensión militar, política, económica y tecnológica entre EEUU y China. Y a ello hay que añadir todo lo relacionado con la búsqueda de vacunas, que, junto a resultados científicos increíbles como disponer de varias de ellas en menos de diez meses y con tecnologías novedosas y prometedoras como el uso de ARN mensajero, ha mostrado con crudeza la importancia geopolítica y geoeconómica de las mismas.

Un quinto y último rasgo por comentar al respecto, en el contexto ya comentado de la confrontación entre China y EE. UU., es el papel divisivo de las relaciones con China en las políticas exteriores y alianzas de la mayoría de los países y en particular de los occidentales. A título de ejemplo, veamos algunas ilustraciones: las acusaciones al "virus chino", popularizadas por el presidente Trump, pero no sólo usadas por él; la diplomacia médica y sanitaria, que ha dado imágenes tan impactantes como la llegada a Italia de brigadas sanitario-militares rusas y chinas; las presiones sobre la tecnología 5G a utilizar en Europa occidental; el debate sobre cómo acabar con la dependencia de bienes sin especial valor añadido pero que en la pandemia se convirtieron en estratégicos como las mascarillas o tapabocas.

Dejaremos de lado, por el momento, otras tendencias importantes que se han acelerado, como la desglobalización o la aparición de un nuevo trilema, que sólo enunciaré. Se trata del trilema entre democracia, salud y economía, que ha aparecido con fuerza durante la pandemia. $Y$, recordemos, un trilema es una situación en que hay que elegir entre tres bienes públicos 0 colectivos, porque sabemos que solo se pueden lograr dos a la vez con éxito. El mundo ha elegido de forma diferente, en sus diferentes regiones, y con impactos claramente perceptibles, entre diferentes pares de esos tres bienes. Y habrá que seguir haciéndolo en el futuro, porque sabemos que habrá nuevas pandemias e, incluso, que, pese a que se haya iniciado el proceso de vacunación en los países occidentales, queda mucho tiempo para alcanzar la inmunidad de grupo (exige entre un $70 \%$ y $80 \%$ de la población 
mundial vacunada), y ello suponiendo que se asegure el acceso seguro y gratuito a la vacunación del Sur global, algo en absoluto garantizado ni probable en este momento.

\section{Una pauta para seguir analizando e investigando}

Empecé aludiendo, vía anécdota de la respuesta de Zhou Enlai, a la importancia de no extraer conclusiones ni lecciones aprendidas en caliente de procesos de cambio en fases tempranas. $Y$ he mantenido que la pandemia está tanto acelerando tendencias ya presentes como provocando, seguramente, impactos disruptivos en el mundo del presente. Pero, lo fundamental es que, en el momento de escribir estas líneas, no tenemos suficientes elementos de juicio racional para dilucidar hasta qué punto la pandemia cambiará reglas de juego y escenarios de futuro, aunque en muchos aspectos de la vida económica, social y política, realmente necesitamos con urgencia algunos cambios radicales.

Por ello, propongo seguir con atención en los próximos tiempos, cinco factores y fuerzas motrices que, si se dan, pueden realmente significar cambios en nuestro mundo:

1. Una nueva comprensión de la importancia de las cadenas de aprovisionamiento y transporte, así como de sus debilidades y vulnerabilidades, para la provisión de bienes críticos, estratégicos ante la certeza de que nuevas pandemias son inevitables. Ello puede conllevar, de darse, modificaciones sustanciales que generen relocalizaciones, reindustrialización y diversificación.

2. Un incremento, a través de la ventana de oportunidad que se ha abierto durante la pandemia, de la cooperación científico-tecnológica y la creación de enfoques globales, y con competencias reales, que permitan una gobernanza efectiva de los problemas de salud global, haciendo de la OMS un actor con capacidad real de actuación.

3. La aceleración del uso de las posibilidades de las tecnologías de la información y de la comunicación, con un crecimiento significativo del mundo digital y la comunicación abierta, tanto en lo laboral como en lo político.

4. Cambios sustantivos en las prácticas económicas y extractivas, las pautas de consumo, en el modo de vida y el capitalismo rampante que tomen en serio la necesidad de hacer frente a los grandes desafíos 
medioambientales, con el cambio climático en un lugar muy destacado, pues, la pandemia, con su rapidísima propagación, es inseparable de la movilidad de personas, animales y mercancías (globalización) y del cambio climático y la constante utilización de zonas selváticas y ricas en biodiversidad.

5. Crecientes demandas, activismo político y social en pro de mayor participación real y constante de los ciudadanos, reformas democráticas y formas de gobierno y de gobernanza más eficaces y que persigan objetivos de bienestar colectivo a medio y largo plazo.

Seguir la evolución -a nivel global, regional y local- de estos cinco factores nos permitirá ver hasta qué punto, dónde y cómo la pandemia está siendo una fuerza de transformación radical, un game-changer.

Menudean las incógnitas y seguimos en el reino de la incertidumbre. Y la ciencia no resolverá la dificultad de la toma de decisiones. Como dijo Emil du Bois-Reymond en el siglo XIX, "ignoramos et ignorabimus", ignoramos e ignoraremos. Decidir implica elegir, por supuesto con la prudencia (frónesis) que recomendaba Aristóteles, y ha llegado el momento de hacerlo. Si permiten, la pandemia ha traído a colación un dicho del mundo clásico, derivado de una fábula de Esopo, que se usaba cuando alguien fanfarroneaba de que podía hacer no importa qué (en la fábula, cuando sostenía que él en Rodas había saltado mucho más): hic Rhodus, hic salta; esto es Rodas, salta aquí. La pandemia nos abre una ventana de oportunidad para saltar y cambiar el curso de la humanidad; el tiempo nos dirá si ha habido salto, en qué dirección y con qué fuerza y resultado.

Diciembre 2020. 